\title{
The effectiveness of articaine in mandibular facial infiltrations
}

This article was published in the following Dove Press journal:

Local and Regional Anesthesia

18 December 2015

Number of times this article has been viewed

\section{Dennis F Flanagan \\ Windham Dental Group, Willimantic, CT, USA}

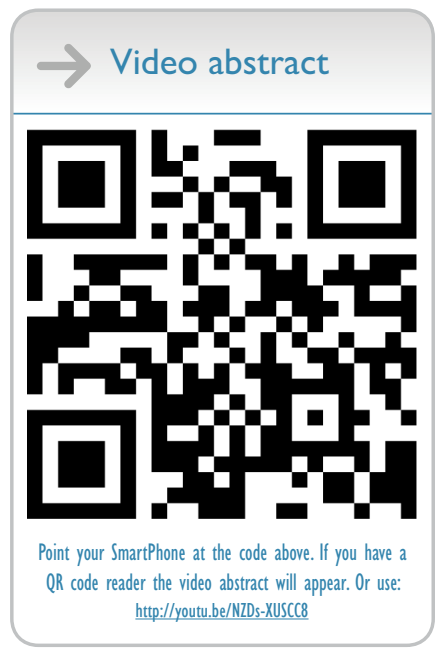

Correspondence: Dennis F Flanagan Windham Dental Group, I67I Main Street, Willimantic, CT 06226, USA

Tel + I 8604563153

Fax + I 8604568759

Email dffdds@comcast.net
Abstract: Four percent articaine local anesthetic has been successfully used to attain local anesthesia for dental procedures. Mandibular block anesthesia may consume longer time to attain and have a higher failure of local anesthesia compared to infiltration. Mandibular facial infiltration has been reported to successfully attain effective local anesthesia for dental procedures. This study involved only several tooth sites and found that $1.8 \mathrm{cc}$ of $4 \%$ articaine facial infiltration in the mandible may be effective when the facial mandibular cortex is $<2.0-3.0 \mathrm{~mm}$. A waiting time of 5-10 minutes may be required for effective anesthesia. An additional $1.8 \mathrm{cc}$ of dose may be required to attain anesthesia if an initial $1.8 \mathrm{cc}$ of dose fails. The need for additional anesthetic may be predicted by a measurement of the facial cortex using cone beam computerized tomography A study of mandibular sites is needed to delineate the anatomical dimensions, density of cortical bone, and apical neural location for ensuring successful local anesthetic infiltration.

Keywords: articaine, local anesthesia, infiltration, dental implant, dental restoration

\section{Introduction}

Articaine (Septocaine) is a relatively recently developed local anesthetic. ${ }^{1}$ It is provided in a $4 \%$ solution, which is twice the usual concentration of $2 \%$ lidocaine (Xylocaine). Articaine is an amide local anesthetic with a thiophene ring instead of a benzene ring in the chemical structure that is found in lidocaine. ${ }^{2}$ Articaine is metabolized quickly, usually within 30-60 minutes, and can produce profound local anesthesia for dental procedures. ${ }^{2}$ It is hydrolyzed by esterases in the blood and thus may have less potential for toxicity. ${ }^{2,3}$ Articaine has become very popular with dentists as a local anesthetic for dental procedures. ${ }^{2,3}$

Generally, infiltration is performed for maxillary procedures and block anesthesia is used for many mandibular sites with $2 \%$ local anesthetics. Studies on the usage of $2 \%$ lidocaine for mandibular infiltrations have been carried out and found to be inferior to articaine. ${ }^{4}$ Articaine facial infiltrations in the mandible have been mostly successfully performed with adequate local anesthesia (Figure 1). Recent studies conflict this point..$^{4-6}$ These studies showed variation in adequate anesthesia. However, these studies did not take into account the anatomical qualities of the injection sites. Mandibular lingual infiltration was shown to be less effective than facial infiltrations. ${ }^{7}$ This may be due to the relatively thicker nature of the mandibular lingual cortex. ${ }^{8}$ The risk of injury to a major blood vessel is negligible during mandibular infiltration. ${ }^{9}$

To minimize the amount of the drug delivered and the risk for failed anesthesia by an inferior alveolar nerve (IAN) block, many clinicians infiltrate articaine submit your manuscript $\mid$ www.dovepress.com

Dovepress

http://dx.doi.org/1 0.2147/LRA.S94647
Local and Regional Anesthesia 2016:9 I-6

(c) (7) (c) 2016 Flanagan. This work is published by Dove Medical Press Limited, and licensed under Creative Commons Attribution - Non Commercial (unported, v3.0) License. The full terms of the License are available at http://creativecommons.org/licenses/by-nc/3.0/. Non-commercial uses of the work are permitted without any further permission from Dove Medical Press Limited, provided the work is properly attributed. Permissions beyond the scope of the License are administered by Dove Medical Press Limited. Information on how to request permission may be found at: http://www.dovepress.com/permissions.php 


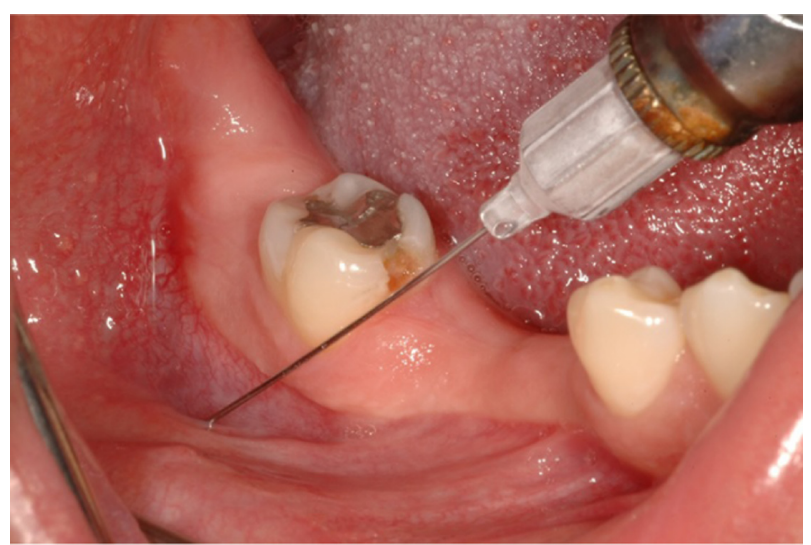

Figure I Mandibular infiltration is delivered to the facial aspect of the mandible.

(Septocaine) facially in the mandible. This technique may be more reliable than the IAN block. ${ }^{5,10}$ However, this author has noticed that facial infiltration in the mandible has a much better successful anesthesia when placed in a site where the bone is palpably concave. When the osseous surface is convex, there seems to be less successful anesthesia. It may be that cortical thickness or density and/or distance of the tooth apex from the facial surface of the mandible surface are factors that may prevent or lessen the anesthetic effect. Is the variation in successful anesthesia due to the thickness of the facial cortex or the distance of the anesthetic bleb to the tooth apex?

The objective of this article is to discuss if mandibular cortical thickness and density and the distance of the tooth apex from the facial aspect of the mandibular cortex are factors that affect successful local infiltration anesthesia with $4 \%$ articaine infiltration in the mandible (Figure 1). ${ }^{11}$

\section{Materials and methods}

Nine caucasian patients in a private general dental practice in eastern Connecticut, USA who had a record of previous diagnostic mandibular cone beam computerized tomography (CBCT) for presurgical evaluation of dental implant, tooth extraction, or third molar surgery were selected for these measurements. There were five females and four males with age ranging from 22 to 69 years. This retrospective study was deemed exempt from ethics approval and acquiring patient consent. Some patients had multiple sites. Each patient had a dental procedure planned for a mandibular tooth or partially edentulous site. The procedures were tooth restoration, tooth extraction, or placement of dental implant. Tested teeth for dental implant procedures were adjacent to the edentulous implant sites. The subject's tooth was initially electrically pulp tested with a battery-operated pulp tester (Pulp Dent) to confirm tooth vitality. This was done as a normal course of treatment to evaluate the quality of the anesthesia before operating. An infiltration of $1.6 \mathrm{cc}$ of $4 \%$ articaine (Septocaine) was then delivered at the facial aspect of the cortical bone directly opposite the perceived apex of the subject tooth. The time was then set to zero. At 2, 5, and 10 minutes, the tooth was again subjected to an electric pulp test to test for adequate anesthesia. When the electric pulp test was negative, the tooth was deemed insensate; the dental procedure was then performed. If the patient reported sensation, ie, positive electric pulp test, the tooth was deemed sensate. After 10 minutes of failed anesthesia, a mandibular block was performed to ascertain adequate anesthesia to accomplish the procedure. Figure 2 demonstrates the CBCT measurement of cortical thickness and distance from the tooth apex to the facial aspect of the cortex. Table 1 lists the time elapsed for electric pulp testing, the facial cortical thicknesses of each site, and the apical to cortical distance of each subject tooth. Apical foramina were seen on most CBCTs, but if not, it was assumed that the apical foramina were at the root apex and were not at the side of the root exiting canals. Measurements were taken using the CBCT of Hounsfield units (HU), the apical cortical thickness of each site, and the distance from the tooth apex to the facial aspect of the facial cortex (Figure 2). HU were read as cortical and trabecular readings (cortical/trabecular) (Table 1). Reading HUs using the CBCT screen produced a range of values, so an approximation of most seen numbers was noted.

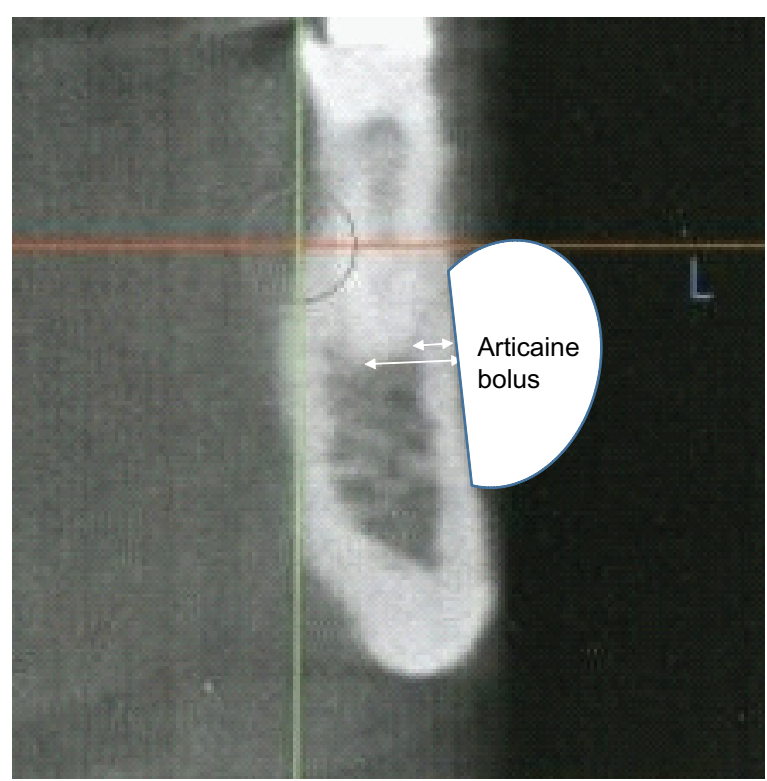

Figure 2 Measurements were taken on the CBCT from the tooth apex to the facial aspect of the mandible and the thickness of the cortex at that location. Abbreviation: $\mathrm{CBCT}$, cone beam computerized tomography. 
Table I An electrical pulp tester was used to determine if the subject tooth was anesthetized at 2, 5, and 10 minutes after infiltration of articaine

\begin{tabular}{|c|c|c|c|c|c|c|c|c|}
\hline Patient & $\begin{array}{l}\text { Tooth } \\
\text { number }\end{array}$ & $\begin{array}{l}\text { Apical } \\
\text { cortical } \\
\text { thickness on } \\
\text { CBCT }(\mathrm{mm})\end{array}$ & $\begin{array}{l}\text { Apex to facial } \\
\text { cortex on } \\
\text { CBCT }(\mathrm{mm})\end{array}$ & $\begin{array}{l}\text { Pulp test at } \\
2 \text { minutes }\end{array}$ & $\begin{array}{l}\text { Pulp test at } \\
5 \text { minutes }\end{array}$ & $\begin{array}{l}\text { Pulp test at } \\
10 \text { minutes }\end{array}$ & $\begin{array}{l}\text { Approximate } \\
\text { cortical/ } \\
\text { trabecular } \\
\text { HU values }\end{array}$ & Procedure \\
\hline \multirow[t]{2}{*}{ Patient I } & $19 M$ & $3.20 \mathrm{M}$ & $4.6 \mathrm{M}$ & + & + & + & $1,360 / 190$ & Restoration \\
\hline & $19 \mathrm{D}$ & $3.30 \mathrm{D}$ & $4.70 \mathrm{D}$ & + & + & + & $1,32 \mid / 167$ & \\
\hline Patient 2 & 22 & 1.35 & 5.14 & + & + & - & $801 / 167$ & Adjacent implant \\
\hline Patient 3 & 23 & 1.15 & 2.24 & + & + & - & $1,230 / 345$ & Adjacent implant \\
\hline Patient 4 & 31 & 1.67 & 3.65 & + & + & - & I,022/442 & Extraction \\
\hline \multirow[t]{4}{*}{ Patient 5} & 22 & 1.83 & 6.23 & + & + & - & $940 / 580$ & Extraction \\
\hline & 25 & 1.35 & 3.27 & + & + & - & $951 / 568$ & Extraction \\
\hline & 26 & 1.11 & 3.81 & + & + & - & $294 / 179$ & Extraction \\
\hline & 27 & 2.33 & 4.96 & + & + & - & $858 / 24 I$ & Extraction \\
\hline Patient 6 & 22 & 1.72 & 3.01 & + & - & - & $960 / 444$ & Extraction \\
\hline Patient 6 & 27 & 1.76 & 2.99 & + & - & - & $824 / 647$ & Extraction \\
\hline \multirow[t]{4}{*}{ Patient 7} & 21 & 2.33 & 4.44 & + & + & - & $1,253 / 256$ & Adjacent implant \\
\hline & 22 & 2.62 & 4.47 & + & + & - & I,405/848 & Adjacent implant \\
\hline & 27 & 2.93 & 4.12 & + & + & - & $\mathrm{I}, 508 / 624$ & Adjacent implant \\
\hline & 28 & 1.74 & 4.48 & + & + & - & I,444/477 & Adjacent implant \\
\hline \multirow[t]{3}{*}{ Patient 8} & 20 & 1.60 & 6.29 & + & - & - & 487/27I & Adjacent implant \\
\hline & 21 & 2.17 & 5.18 & + & - & - & $831 / 203$ & Adjacent implant \\
\hline & 22 & 2.60 & 4.54 & + & + & - & $520 / 28 I$ & Adjacent implant \\
\hline \multirow[t]{2}{*}{ Patient 9} & 22 & 2.06 & 5.34 & + & - & - & $636 / 361$ & Restoration \\
\hline & 27 & 2.66 & 5.11 & + & - & - & I,328/424 & Restoration \\
\hline
\end{tabular}

Notes: Each cortical thickness was measured using the CBCT. Each distance from the tooth apex to the facial aspect of the cortex was measured using the CBCT. Cortical and trabecular HU values were measured for each site. Each tooth was slated for a restoration, an extraction, or an adjacent edentulous implant. All teeth were sensate at zero start time and after 2 minutes. After 5 minutes, 14 teeth were sensate and six were insensate. After 10 minutes, all teeth were insensate except one first molar. $+=$ sensate, $-=$ insensate.

Abbreviations: $\mathrm{CBCT}$, cone beam computerized tomography; HU, Hounsfield units; M, mesial; D, distal.

\section{Results}

At 0 and 2 minutes post infiltration time, all teeth responded to the electrical pulp testing.

Patients who had an average cortical thickness of $2.12 \mathrm{~mm}$ with a range of $1.11-3.20 \mathrm{~mm}$ facial cortical thickness reported "sensation" at 5 minutes to the electric pulp test.

Patients who had an average cortical thickness of $2.0 \mathrm{~mm}$ with a range of 1.60-2.66 mm facial cortical thickness reported "no sensation" at 5 minutes to the electric pulp test.

At 10 minutes, the only patient who was still sensate had a two-root mandibular left first molar with an average facial cortical thickness of $3.25 \mathrm{~mm}$ (Tables 1-3). The mandibular left first molar had two separate roots and was measured as two separate teeth. The remaining insensate teeth had an average cortical thickness of $1.94 \mathrm{~mm}$.
Patients who had an average apex to facial cortex distance of $4.33 \mathrm{~mm}$ with a range of $2.24-6.23 \mathrm{~mm}$ facial cortical thickness reported "sensation" at 5 minutes to the electric pulp test.

Patients who had an average apex to facial cortex distance of $4.65 \mathrm{~mm}$ with a range of $2.99-6.29 \mathrm{~mm}$ facial cortical thickness reported "no sensation" at 5 minutes to the electric pulp test.

At ten minutes for Patient 1, the two root molar remained sensate. Each tooth apex was $4.6 \mathrm{~mm}$ and $4.7 \mathrm{~mm}$ to the facial cortex. The average was $4.65 \mathrm{~mm}$.

The position of the tooth apex from the facial aspect of the cortex did not appear to be a factor in the attainment of anesthesia.

Patients who had a cortical/trabecular average of $1,065 / 383 \mathrm{HU}$ reported "sensation" at 5 minutes to the electric pulp test (Table 4).

Table 2 The average cortical thicknesses of each site were calculated

\begin{tabular}{|c|c|c|c|}
\hline $\begin{array}{l}\text { Average cortical } \\
\text { thickness }(\mathrm{mm})- \\
\text { sensate at } 5 \text { minutes }\end{array}$ & $\begin{array}{l}\text { Average cortical } \\
\text { thickness }(\mathrm{mm})- \\
\text { insensate at } 5 \text { minutes }\end{array}$ & $\begin{array}{l}\text { Average cortical thickness }(\mathrm{mm}) \text { - } \\
\text { sensate at } 10 \text { minutes } \\
\text { (one molar with two roots) }\end{array}$ & $\begin{array}{l}\text { Average cortical thickness }(\mathrm{mm})- \\
\text { insensate at } 10 \text { minutes }\end{array}$ \\
\hline 2.12 & 2.00 & 3.25 & 1.94 \\
\hline
\end{tabular}

Note: The thickest cortices did not attain anesthesia. 
Table 3 The average apex to facial cortex distance was measured

\begin{tabular}{lll}
\hline $\begin{array}{l}\text { Average apical } \\
\text { distance }(\mathbf{m m})-\end{array}$ & $\begin{array}{l}\text { Average apical } \\
\text { distance }(\mathbf{m m})-\end{array}$ & $\begin{array}{l}\text { Average apical } \\
\text { distance }(\mathbf{m m})-\end{array}$ \\
sensate at $\mathbf{5}$ minutes & insensate at $\mathbf{5}$ minutes & sensate at $\mathbf{~} \mathbf{0}$ minutes \\
\hline 4.33 & 4.65 & 4.65 \\
\hline
\end{tabular}

Note: The position of the tooth apex from the facial aspect of the cortex did not appear to influence the attainment of anesthesia.

Patients who had a cortical/trabecular average of $844 / 392$ HU reported "no sensation" at 5 minutes to the electric pulp test.

The patient at site 19 who had a cortical/trabecular average of 1,341/179 HU reported persisting "sensation" at 10 minutes to the electric pulp test (Table 4).

Patients who had an average of 961/409 HU reported "no sensation" at 10 minutes (Table 4).

The higher HU cortical values were associated with "sensation", while higher trabecular HU values were associated with "no sensation". There was no association of HU with onset of anesthesia.

Age and sex did not influence outcomes.

\section{Discussion}

Previous work on using mandibular facial and lingual infiltration found a $56 \%$ successful anesthesia with $1.8 \mathrm{cc}$ and $93 \%$ successful anesthesia with $3.6 \mathrm{cc} .{ }^{12}$ This study had supplemental lingual infiltration to augment the facial infiltration. Osseous qualities were not noted, and the most successful anesthesia was obtained with a "double dose" of the articaine. The additional drug delivered may have more successfully anesthetized the teeth tested. Another study using double infiltration dose $(3.8 \mathrm{~mL})$ of $4 \%$ articaine demonstrated a production of anesthesia of mandibular first molars in $70 \%$ of patients. ${ }^{6}$ The extra articaine may provide enough drug quantity to penetrate cortical thickness or osseous nutrient canals. ${ }^{13}$ There was not $100 \%$ effective anesthesia, which may be due to thicker cortices at these sites.

The onset of articaine local anesthesia is generally 7-9 minutes for mandibular blocks. ${ }^{14}$ For a local anesthetic to act, it must be in physical contact with the neurons to be anesthetized. With facial infiltrations, access to these nerves requires that the articaine penetrates the cortical and trabecular bone to be in contact with the apical neural supply. Cortical bone is permeable to nutrients, waste products, and signal molecules. ${ }^{15}$ Articaine would most likely permeate cortex as well. However, increased cortical thickness may attenuate the passage of molecules. Intraosseous lipids and the osseous collagen matrix constituents of a particular bone site and canalicular distribution may influence permeability. ${ }^{15,16}$ Thus, different sites on a bone or different bones may allow drug penetration more or less depending on the microanatomy and biochemistry of a particular osseous site. Vancomycin and glycopeptides penetrate bone, but penetration is improved with an increased osseous vascularization. ${ }^{17}$ Increased molecular penetration also occurs in the presence of inflammation and decreases with impaired vascularization. ${ }^{18}$ However, inflamed sites may have a low $\mathrm{pH}$ and reduce anesthetic disassociation for bioactivity.

In one prospective randomized trial, articaine was used to anesthetize mandibular teeth with irreversible pulpitis. It was found that after failure of an IAN block with $2 \%$ lidocaine and 1:100,000 epinephrine, a facial infiltration with $4 \%$ articaine and 1:100,000 epinephrine produced successful tooth anesthesia in $84 \%$ of the failed cases. ${ }^{19}$ Facial infiltration with articaine may provide additional or complete anesthesia for treatment of irreversible pulpitis. The inflammation occurs intrapulpally, so this would not affect anesthetic disassociation. Nevertheless, the articaine infiltration did not provide $100 \%$ effective anesthesia.

A prospective randomized, double-blind, crossover study compared the pulpal anesthesia attained with $4 \%$ concentrations of articaine, lidocaine, and prilocaine as primary buccal infiltrations of the mandibular first molar. ${ }^{20}$ The effectiveness of $4 \%$ articaine at $55 \%$ was more than $4 \%$ lidocaine at $33 \%$ and $4 \%$ prilocaine at $32 \% .{ }^{20}$

In another study by Rogers et al, rescue infiltration with $1.7 \mathrm{cc}$ articaine (62\%) after failed IAN block was more successful than lidocaine ( $62 \%$ vs $37 \%){ }^{21}$

In one study of likely implant sites, long-standing edentulous facial plate thicknesses were measured and found in the range of 1-2.2 mm. ${ }^{8}$ In dentate sites, the facial cortical thickness ranged 1.6-2.2 mm. ${ }^{22}$ Thinner dentate cortices were found in the mandibular anterior, and the thickest cortices were found in the posterior maxilla. A thicker cortex may

Table 4 The HU values for each site, cortical/trabecular, were measured using the CBCT

\begin{tabular}{llll}
\hline $\begin{array}{l}\text { Average } \mathrm{HU}-\text { sensate } \\
\text { at } 5 \text { minutes }\end{array}$ & $\begin{array}{l}\text { Average } \mathrm{HU}-\text { insensate } \\
\text { at } 5 \text { minutes }\end{array}$ & $\begin{array}{l}\text { Average } \mathrm{HU}-\text { sensate } \\
\text { at } 10 \text { minutes }\end{array}$ & $\begin{array}{l}\text { Average } \mathrm{HU}-\text { insensate } \\
\text { at } 10 \text { minutes }\end{array}$ \\
\hline $\mathrm{I}, 065 / 383$ & $844 / 392$ & $1,341 / 179$ & $961 / 409$ \\
\hline
\end{tabular}

Note: $\mathrm{HU}$ measurements using the $\mathrm{CBCT}$ are not accurate for bone density due to technical anatomical factors.

Abbreviations: $\mathrm{HU}$, Hounsfield units; $\mathrm{CBCT}$, cone beam computerized tomography. 
inhibit penetration of an anesthetic solution and thus its effectiveness. In dentate and edentulous sites in the maxilla and mandible, the lingual cortical bone is generally thicker than the facial cortex. ${ }^{8,22}$

CBCT can show small neurovascular nutrient osseous canals that may conduct anesthetic solution into the cancellous bone to the apical end of the tooth. ${ }^{23}$ The resolution of any particular CBCT may not show very small nutrient osseous canals that may be numerous and that may conduct anesthetic solution. Nutrient canals that perforate the mandibular cortex may allow small amounts of anesthetic into the medullary space and thus may act on the dental nerve. ${ }^{18}$ Canal dimensions may vary from $0.4 \mathrm{~mm}$ to $1.8 \mathrm{~mm} .^{24}$ However, many of these canals may be very small and may not individually conduct adequate amounts of anesthetic for a clinical effect. Diffusion of the anesthetic through thin cortical bone may be effective. Often a facial infiltration of $4 \%$ articaine in the mandible will produce anesthesia in the more anterior teeth, such as the canines or incisors. The anterior mandible appears to have the most nutrient canals. This may be due to the blood supply to this area that originates from the facial artery. ${ }^{9}$ This may be due to the penetration of the anesthetic through nutrient canals and subsequent diffusion to contact dental neurons. ${ }^{13,24}$ Which is more effective, nutrient canal conduction or cortical diffusion, for anesthesia is not known.

The surgical placement of dental implants in edentulous sites may be accomplished with facial and lingual infiltrations of $4 \%$ articaine. ${ }^{12}$ Avoiding the anesthetic block of the IAN may give the implant surgeon important sensory information from the patient if the osteotomy drill approaches this nerve. Anecdotally, the author has had more than a thousand successful implant placements by using facial and lingual infiltrations with $1.8 \mathrm{cc}$ of $4 \%$ articaine in palpably concave sites. However, concavity may not be the single most important quality for anesthetic penetration.

Generally, lidocaine may not be effective in patients with hypokalemic sensory overstimulation, similar to hypokalemic periodic paralysis, a result of mutations in the SCN4A gene. ${ }^{25}$ The phenotype of attention deficit disorder (ADD) is closely related to this hypokalemic disorder, and there may be some types of ADD that render these patients resistant to lidocaine effectiveness. Also articaine may be ineffective in these patients. None of the patients in this study reported hypokalemic sensory overstimulation or ADD.

Articaine has been implicated in IAN and lingual nerve damage during the mandibular block technique, but this is controversial. ${ }^{26,27}$ Most of the reported nerve altered sensa- tion occurs in the lingual nerve, which may be anatomically less well protected than the IAN. ${ }^{3}$ The neural sheath may be thinner in the lingual nerve, which may allow damaging penetration of the high concentration of the articaine preparation. Mandibular block anesthesia with articaine without vasoconstrictor has recently been advocated for use in patients who are restricted from epinephrine. ${ }^{28}$ The epinephrine prolongs the duration of the articaine and may prolong damaging exposure of the nerve to the anesthetic. Facial infiltration of articaine bypasses the mandibular block technique and thus the potential for damage of these neural structures.

HU depicts a bone density value on CBCT images. ${ }^{29}$ The higher cortical HU values were associated with persisting sensation, while higher trabecular HU values were associated with no sensation (Table 4). HU may not be an accurate depiction of the actual bone density, but a broad approximation since anatomical factors may influence the readings. ${ }^{29}$ Thick cortical bone can cause distortions in the measured HU. ${ }^{29}$

It may take at least 5-10 minutes for mandibular facial infiltrations with articaine to be effective in most sites. Thicker cortices are associated with longer onset and no onset of anesthesia. Cortices thicker than $\sim 2.00 \mathrm{~mm}$ may take longer to attain anesthesia or may never become anesthetized. A $3.2 \mathrm{cc}$ dose may be required to attain anesthesia if the cortex is thicker than $2.0 \mathrm{~mm}$.

Clinicians with access to CBCT can measure the facial cortex before infiltration to determine if $1.8 \mathrm{cc}$ or $3.6 \mathrm{cc}$ would be required for adequate anesthesia for a proposed procedure.

No statistical analysis was performed due to a small number of readings and limited diversity of cases.

\section{Conclusion}

A total of $4 \%$ articaine infiltration at the facial aspect of the mandible may produce effective local anesthesia in patients with thinner cortices where the anesthetic is delivered. When there is facial cortical bone thicker than $\sim 2.0 \mathrm{~mm}$, as measured on a CBCT, adequate anesthesia may not occur. Cortical thickness appears to be the primary factor that determines onset of anesthesia. A CBCT can allow measurement of the facial cortex to indicate if a larger dose of anesthetic would be required for adequate anesthesia. Cortical density expressed in HU or tooth apex distance from the facial cortical aspect of the site did not appear to dramatically affect anesthetic effect. A waiting time of 5-10 minutes may be required for effective anesthesia. An additional $1.8 \mathrm{cc}$ of 
dose may be required to attain anesthesia if an initial $1.8 \mathrm{cc}$ of dose fails. The additional anesthetic solution may allow better penetration. More appropriate study of this concept is required to delineate the appropriate cortical thickness, density, trabecular density, and apex-cortex distance dimensions that may affect local anesthesia.

\section{Disclosure}

The author reports no affiliation or connection with any commercial interests, or conflicts of interest in this work.

\section{References}

1. Yapp KE, Hopcraft MS, Parashos P. Articaine: a review of the literature. Br Dent J. 2011;210:323-329.

2. Oertel R, Rahn R, Kirch W. Clinical pharmacokinetics of articaine. Clin Pharmacokinet. 1997;33(6):417-425.

3. Pogrel MA, Bryan J, Regezi J. Nerve damage associated with inferior alveolar nerve blocks. J Am Dent Assoc. 1995;126(8):1150-1155.

4. Meechan JG. The use of the mandibular infiltration anesthetic technique in adults. J Am Dent Assoc. 2011;142(9 Suppl):19s-24s.

5. Robertson D, Nusstein J, Reader A, Beck M, McCartney M. The anesthetic efficacy of articaine in buccal infiltration of the mandibular posterior teeth. JAm Dent Assoc. 2007;138(8):1104-1112.

6. Martin M, Nusstyein J, Drum M, Reader A, Beck M. Anesthetic efficacy of $1.8 \mathrm{~mL}$ versus $3.6 \mathrm{~mL}$ of $4 \%$ articaine with $1: 100,000$ epinephrine as a primary buccal infiltration of the mandibular first molar. $J$ Endod. 2011;37(5):588-592.

7. Corbet IP, Kanaa MD, Whitworth JM, Meechen JG. Articaine infiltration for anesthesia of mandibular first molars. J Endod. 2008; 34(5):514-518.

8. Flanagan D. A comparison of facial and lingual cortical thicknesses in edentulous maxillary and mandibular sites measured on computerized tomograms. J Oral Implantol. 2008;34(5):256-258.

9. Flanagan D. Arterial supply of mandible. J Oral Implantol. 2003;29(4): $165-173$.

10. Braut V, Bornstein M, Lauber R, Buser D. Bone dimensions in the posterior mandible: a retrospective radiographic study using cone beam computed tomography. Part 1- analysis of dentate sites. Int $J$ Periodontics Restorative Dent. 2012;32(2):175-184.

11. Articaine [package insert]. Septodont. Louisville, CO: Novocol Pharmaceuticals of Canada Inc.; Cambridge, ON, Canada N1R 6X3.

12. El-Kholey KE. Infiltration anesthesia for extraction of the mandibular molars. J Oral Maxillofac Surg. 2013;71(10):.e1-.e5.

13. Currie CC, Meechan JG, Whitworth JM, Corbett IP. Is mandibular molar buccal infiltration a mental and incisive nerve block? A randomized controlled trial. J Endod. 2013;39(4):439-443.

14. Tortamano IP, Siviero M, Lee S, Sampaio RM, Simone JL, Rocha RG. Onset and duration period of pulpal anesthesia of articaine and lidocaine in inferior alveolar nerve block. Braz Dent J. 2013;24(4):371-374.
15. Wen D, Androjna C, Vasanji A, Belovich J, Midura RJ. Lipids and collagen matrix restrict the hydraulic permeability within the porous compartment of adult cortical bone. Ann Biomed Eng. 2010;38(3): 558-569.

16. Beno T, Yoon YJ, Cowin SC, Fritton SP. Estimation of bone permeability using accurate microstructural measurements. $J$ Biomech. 2006;39(13):2378-2387.

17. Garazzino S, Aprato A, Baietto L, et al. Glycopeptide bone penetration in patients with septic pseudoarthrosis of the tibia. Clin Pharmacokinet. 2008;47(12):793-805.

18. Malachanne E, Dureisseix D, Cañadas P, Jourdan F. Experimental and numerical identification of cortical bone permeability. $J$ Biomech. 2008;41(3):721-725.

19. Kanaa MD, Whitworth JM, Meechan JG. A prospective randomized trial of different supplementary local anesthesia techniques after failure of inferior alveolar nerve block in patients with irreversible pulpitis in mandibular teeth. $J$ Endod. 2012;38:421-425.

20. Nydegger B, Nusstein J, Reader A, Drum M, Beck M. Anesthetic comparisons of $4 \%$ concentrations of articaine, lidocaine, and prilocaine as primary buccal infiltrations of the mandibular first molar: a prospective randomized, double-blind study. J Endod. 2014;40(12):1912-1916.

21. Rogers BS, Botero TM, McDonald NJ, Gardner RJ, Peters MC. Efficacy of articaine versus lidocaine as a supplemental buccal infiltration in mandibular molars with irreversible pulpitis: a prospective, randomized, double-blind study. J Endod. 2014;40(6):753-758.

22. Katranji A, Misch K, Wang HL. Cortical bone thickness in dentate and edentulous human cadavers. J Periodontol. 2007;78(5):874-878.

23. Fuakami K, Shiozaki K, Mishima A, Shimoda S, Hamada Y, Kobayashi K. Detection of buccal perimandibular neurovascularisation associated with accessory foramina using limited cone-beam computed tomography and gross anatomy. Surg Radiol Anat. 2011;33(2):141-146.

24. Kawashima Y, Sekiya K, Sasaki Y, Tsukioka T, Muramatsu T, Kaneda T. Computed tomography findings of mandibular nutrient canals. Implant Dent. 2015;24(4):458-463.

25. Segal MM, Rogers GF, Needleman HL, Chapman CA. Hypokalemic sensory overstimulation. J Child Neurol. 2007;22(12):1408-1410.

26. Malamed SF. Local anesthetics: dentistry's most important drugs, clinical update 2006. J Calif Dent Assoc. 2006;4(12):971-976.

27. Pogrel MA. Permanent nerve damage from inferior alveolar nerve blocks, an update to include articaine. $J$ Calif Dent Assoc. 2007;5(4): 271-273.

28. Kämmerer PW, Palarie V, Daubländer M, et al. Comparison of $4 \%$ Articaine with epinephrine $(1: 100,000)$ and without epinephrine in inferior alveolar block for tooth extraction: double-blind randomized clinical trial of anesthesia efficacy. Oral Surg Oral Med Oral Pathol Oral Radiol Endod. 2012;113(4):495-499.

29. Brosh T, Yekaterina BE, Pilo R, Shpack N, Geron S. Can cone beam CT predict the hardness of interradicular cortical bone? Head Face Med. 2014;10(1):12.
Local and Regional Anesthesia

\section{Publish your work in this journal}

Local and Regional Anesthesia is an international, peer-reviewed, open access journal publishing on the development, pharmacology, delivery and targeting and clinical use of local and regional anesthetics and analgesics. The journal welcomes submitted papers covering original research, basic science, clinical studies, reviews \& evaluations,

\section{Dovepress}

guidelines, expert opinion and commentary, case reports and extended reports. The manuscript management system is completely online and includes a very quick and fair peer-review system, which is all easy to use. Visit http://www.dovepress.com/testimonials.php to read real quotes from published authors. 